\title{
Editorial: Equity and Diversity
}

\author{
Tracy Riley ${ }^{1} \cdot$ Mandia Mentis $^{1} \cdot$ Alison Kearney $^{1}$
}

Published online: 20 September 2016

(C) New Zealand Association for Research in Education 2016

\section{Introduction}

Why does the theme, 'equity and diversity', warrant a special issue of New Zealand Journal of Educational Studies? The importance of equitable education systems cannot be overstated. Not only is access to fair and inclusive education a basic human right, the provision of equitable education systems brings considerable advantages to individuals and to societies in general. For example, when compared to those with limited educational opportunities, well-educated people have better health, higher incomes, engage more in civic activities and are generally happier (Organisation for Economic Co-operation and Development 2013). Unfortunately, education systems have not always been fair and equitable, with some students experiencing exclusion and marginalisation from and within school on the basis of personal and social factors such as ethnicity, ability/disability, gender, sexuality, and religion.

The factors of ability, ethnicity, culture, and socio-economic status, alongside other differences such as gender, infrastructure and context, are major contributors to people's differing experiences of, participation in, and access to, learning. And while this situation feels acute in New Zealand, it is an international concern. Mel Ainscow places equity and diversity in a contemporary, international context in the opening article by tracing the history of policy developments and initiatives of the Education for All movement. He alerts readers to the importance of the year 2016, with recent developments in the Incheon Declaration and publication of the

Tracy Riley

T.L.Riley@massey.ac.nz

1 Institute of Education Centre for Equity through Education, Massey University,

Palmerston North, New Zealand 
UNESCO Education 2030 Framework for Action clearly signalling that "all forms of exclusion and marginalisation, disparities and inequalities to access, participation and learning processes and outcomes" must be addressed. Ainscow reminds us that the Education for All movement really has to be about 'all' learners. Drawing from his own research findings, Ainscow conceptualises a change agenda, challenging New Zealand policymakers, practitioners, and researchers to work together with children and young people to improve the presence, participation, and achievement of all, regardless of difference. Engaging with difference can, in Ainscow's words, be "a powerful catalyst" for change.

The researchers in this special issue have engaged with difference by examining policies within a New Zealand context from the perspectives of young children and those with disabilities; listening to the voices of Pāsifika peoples, gifted and talented students, and professionals working in the disability sectors; and working with parents to create home-school interventions for literacy. The articles only just begin to tap into the complexities of understanding and achieving equity, but by no means comprehensively engage with the many voices of diversity and potential catalysts for change. Nonetheless, this issue highlights the principles of fairness and justice, as they relate to pedagogies, policies, and practices, across the different dimensions of culture, language, and ability. The authors have taken up Ainscow's challenge by starting a conversation that will support New Zealand educators in the development of shared understandings of equity and ways of moving thinking and practice forward.

The second article, by Jude MacArthur and Gill Rutherford, shifts the focus to New Zealand with a critique of current policy and practice. The authors endorse the positioning of education for all as a children's rights issue, rather than a special or inclusive education issue. They argue that a rights framework recognises diversity and disability, without favour to some and disregard for others; in other words, it is more equitable. MacArthur and Rutherford imagine what an equitable education could be, and go on to re-write one of the Ministry of Education's case study scenarios from a rights-informed perspective. As the authors explain, "this special edition offers an opportunity to think about a way to do things differently in education, a way that eschews 'special' and instead builds on children's rights." The authors end their article be asserting that we already know more than we need to know in order to ensure an equitable education in New Zealand, but we are challenged to confront the fact that we have not yet done so.

The next article, again, examines New Zealand policy, with Tara McLaughlin, Karyn Aspden, and Patricia Snyder, arguing that our policy focus on participation, without attention to quality of experience, puts young children at risk. They propose a re-focus on intentional teaching- "the purposeful and deliberate actions of teachers, drawing on their knowledge of individual children and informed by professional knowledge and skills." The article examines guidance given to teachers in New Zealand, Australia, and the United States of America that helps guide intentional teaching. The authors argue that intentional teaching should result in meaningful and appropriate curricular experiences for all learners in early childhood education. 
Teacher knowledge of learners' cultures and values is part of intentional teaching, and the next article redirects readers' focus to our models of culturally responsive teaching that support equitable learning opportunities for Pāsifika students. Drawing from the results of five different studies, authors Jodie Hunter, Roberta Hunter, Barbara Hannant, Kevin Kritesh, Rakesh Lachaiya, Trevor Bills, and Ingrid Cheung, illustrate how culture and values influence the learning and engagement. The authors illuminate the importance of language, family, and respectful relationships, all of which are embedded in core Pāsifika values that are sometimes misinterpreted cross-culturally. The article provides exemplars that demonstrate "equitable outcomes for Pāsifika students and their families when educators relate to them as culturally located people with rich funds of knowledge to contribute."

The fifth article develops this need to understand and respect difference by exploring the perspectives of gifted students, their parents, and teachers. Tracy Riley and Vanessa White report the findings of a New Zealand study which examines opportunities for gifted learners to engage with like-minded peers. They argue that engagement with like-minded peers facilitates opportunities for belonging and connectedness, which in turn, removes a potential barrier to achievement for gifted learners. This article challenges arguments that giftedness is exclusionary, by positioning gifted provisions as expressions of equity-opportunities to learn and be challenged in one's strengths and abilities.

Julia Budd's research investigates the complexities of understanding equity for people experiencing disability. Equitable practices and outcomes for those experiencing disabilities are especially complicated by the different perspectives held by cross-disciplinary groups. In her article, she discusses how a metaperspective can be useful to map and explore different paradigms of disability. Budd argues that an examination of meta-perspectives helps build common ground and facilitate cross-disciplinary understanding and collaboration. She introduces critical realist meta-perspectives to show how different paradigms and disciplines work at "different levels and scales of reality"-potentially illuminating new ways of seeing the equity issues experienced by those with disabilities.

The theme of working together is further developed in the seventh article in this special issue. Jayne Jackson reports on one student's experience of a clash between rich literacy practices at home which were not recognised at school. The approach to literacy described by Jackson prioritises the home reading environment, positioning parents as experts in their child's reading. The partnership that develops between Jackson, as a researcher, and the family of one child, acknowledges the values, interests and knowledge of families, and legitimises a broad range of literacy practices as equitable.

We are delighted to be able to include the 2015 Herbison Lecture by Joce Jesson. Emancipation through Education, The Dreams of Organised Teachers: Remembering our History. The address captures elements of 'forgotten history' that have shaped education in our country. We are challenged to think about what we want New Zealand to be like and the model of nationhood that we want education to support. 
We feature a commentary from John O'Neill reflecting on recent special education policy announcements in terms of their official rationality. Commentaries provide the opportunity to make original observations on a particular issue, and in this issue, O'Neill foregrounds a flaw in the Minister of Education's claim to promote greater equity in education through 'modernising' learning support and redistributing funding from 2017 when the policy comes into effect. He outlines how if the same amount of funding is redirected to some learners, other learners, who currently receive funding, will inevitably be adversely affected.

The journal concludes with a review of five books, which have a strong focus on the theme of this special edition. First, Mandia Mentis provides a review of Children's Rights, Educational Research and the UNCRC: Past, Present and Future edited by Jenna Gillet-Swan and Vicki Coppock and Alison Kearney reviews Locked out: Understanding and Tackling School Exclusion in Australia and Aotearoa New Zealand edited by Patty Towl and Sheryl Hemphill. Andrea Gilkison has reviewed Critical Narrative and Pedagogy by Ivor Goodson and Scherto Gill. Mentoring in Early Childhood Education: A Compilation of Thinking, Pedagogy and Practice, edited by Caterina Murphy and Kate Thornton, is reviewed by Maria Cooper. Finally, Jenny Ritchie reviews the book, Sociocultural Realities: Exploring New Horizons, edited by Angus MacFarlane, Sonja MacFarlane, and Melinda Webber.

Thank you to all who contributed to this special issue: the authors; reviewers; NZJES editors, Roseanna Bourke and Judith Loveridge; and NZJES book review editor, Stephanie Doyle. We hope readers of this special edition are challenged to consider ways in which diverse students are excluded and marginalised, and how our practices may contribute to the creation of more equitable education systems.

\section{Reference}

Organisation for Economic Co-operation and Development. (2013). Education indicators in focus. Retrieved from https://www.oecd.org/education/skills-beyond-school/EDIF\%202013-N\%C2\% B010\%20(eng)-v9\%20FINAL\%20bis.pdf. 